\title{
Adaptation of Modified Shrinking Core Model for the Description of Salicylic Acid Adsorption on Olive Stones Activated Carbons
}

\author{
Thouraya Bohli", Ghofrane Hamdi, Souaad Suissi Najjar, Abdelmottaleb Ouederni \\ Chemical Engineering Department, National School of Engineers of Gabes, University of Gabes, Gabes, Tunisia
}

Email address:

bohlithouraya@gmail.com (T. Bohli)

${ }^{*}$ Corresponding author

\section{To cite this article:}

Thouraya Bohli, Ghofrane Hamdi, Souaad Suissi Najjar, Abdelmottaleb Ouederni. Adaptation of Modified Shrinking Core Model for the Description of Salicylic Acid Adsorption on Olive Stones Activated Carbons. Advances in Bioscience and Bioengineering.

Vol. 5, No. 3, 2017, pp. 42-50. doi: 10.11648/j.abb.20170503.12

Received: April 8, 2017; Accepted: April 27, 2017; Published: October 18, 2017

\begin{abstract}
This work aimed to apply a modified shrinking core model (SCM) for describing the kinetic adsorption process of a solute in a microporous activated carbon in an agitated finite batch aqueous system. To apply the SCM, the diffusionadsorption process in the pore of the adsorbent is transposed to a diagram of diffusion-reaction according to a mobile front. Indeed, solid adsorbent particle is assumed formed by two layers. The first layer is an inner core, not yet reached by the adsorbate, and the second layer is an outer shell, where diffusion and binding to particle sites are occurring. In this study, two mass transfer resistances are considered; the external liquid film resistance and intraparticle resistance. The developed modified SCM, applied to experimental data for the adsorption of salicylic acid onto olive stone activated carbons and a commercial one, give a more realistic prediction and shows a good accuracy in describing batch adsorption in mixed suspension. The kinetic parameters: the effective diffusivity and the mass transfer coefficient were determined. Using the estimated parameters, a parametric study was carried out to observe the effects of the particle size of adsorbent, the initial adsorbate concentration and the stirring velocity on the system kinetics.
\end{abstract}

Keywords: Shrinking Core Model, Mass Transfer Coefficient, Effective Diffusivity, Salicylic Acid, Olive Stones, Activated Carbon, Kinetic, Adsorption

\section{Introduction}

Water pollution is currently the worldwide subject of important interest, thus its treatment became one of the more urgent environmental concerns that researchers are facing. Among a variety of organic pollutants, phenolic compounds are considered by many environmental organizations as hazardous contaminants of water causing an unpleasant taste and odor even at low concentration $[1,2]$, harmful and with a potential toxicity to animals and human health [3]. Phenolic compounds are widely used in industries involving pulp and paper, petroleum refinery, pharmaceutical, dye synthesis, phenolic resin manufacturing, coal gasification $[4,5]$. Therefore, the removal or the reduction of phenolic compounds level in wastewaters need specific and appropriate treatment technique. Among developed wastewaters treatment processes, adsorption is still regarded as the best alternative based on its performances to meet the effluent discharge standards especially when a low cost adsorbent was used, its flexibility in design and operation [6]. Activated carbon is one of the widely used industrial adsorbents and carboneous materials. Activated carbon is characterized by a well-developed internal pore structure, high surface area and diversifies chemical functional groups located at the outer and inner surfaces [7, 8]. Preparation of activated carbon from low cost renewable agricultural byproducts is chosen by some researchers to reduce the cost of the adsorption process $[9,10]$. Although that in industrial scale fixed bed adsorbers are commonly used to treat big volumes of wastewaters with continuous feed flow, 
adsorption studies in agitated finite batch adsorbers are necessary since they give important equilibrium and kinetic data, from which, parameters such as the effective pore diffusion of the pollutant can be evaluated and becomes useful for further fixed bed studies and for the prediction of industrial adsorber performance [11-13]. In fact, adsorptive mass transfer of pollutant from liquid phase to adsorption sites of adsorbent is governed by the external liquid film resistance and the pore diffusion resistance in series. Some similarities exist between the adsorption by porous solids phenomena and the noncatalytic fluid-solid reactions with an invariant volume. For this reason, more attention has been focused recently on the use of the shrinking core model (SCM) to describe the adsorption kinetics in batch or fixed system [13-16]. The shrinking core model considered that solid particle is formed by two layers. The first layer is an inner core, not yet reached by the adsorbate, and the second layer is an outer shell, where diffusion and binding to adsorbent sites are occurring; the reacted shell is saturated with adsorbate throughout the process as the front advances inward through the particle and the unreached core shrinks [17]. As hypothesis for SCM, the adsorption kinetic reaction is considered to be fast as compared to mass transport, so that the adsorbate inside the pore volume is in local equilibrium with the adsorbate attached to the pore walls [17-21]. Therefore, pseudo-steady state conditions can be assumed when the front advances slowly in comparison to the rates of the adsorption or immobilization and transport.

In the present investigation, a modified shrinking core model was used to simulate experimental kinetic curves resulted from the adsorption of salicylic acid from synthetic solution, using microporous activated carbons prepared from olive stones renewable agriculture by-products as adsorbents. By considering a batch mixed suspension of $\mathrm{AC}$, the effect of AC size particle, initial concentration of salicylic acid and stirring velocity on the system kinetics were studied and both the external liquid film resistance $\left(\mathrm{k}_{\mathrm{f}}(\mathrm{m} / \mathrm{s})\right.$ and the pore diffusion resistance $\left(D_{e}\left(\mathrm{~m}^{2} / \mathrm{s}\right)\right)$ were evaluated.

\section{Theoretical}

\subsection{Development of Modified SCM Equations}

The current assumptions made in this model, where sorbent particles are spherical with a uniform radius, are the following:

(1) Adsorption isotherm is reversible;

(2) Effective diffusivity is constant;

(3) Pseudo steady-state approximation is valid;

(4) The driving force in both film and particle mass transfer is linear.

As in the SCM, the adsorbate advances as a topochemical inward-moving spherical front at $r=R_{f}(t)$. This interface separates the particle into an inner core $0<\mathrm{r}<\mathrm{R}_{\mathrm{f}}(\mathrm{t})$ not yet reached by the adsorbate and an outer shell $\mathrm{R}_{\mathrm{f}}(\mathrm{t})<\mathrm{r}<\mathrm{R}$ where diffusion and binding to bead sites are occurring (Figure1):

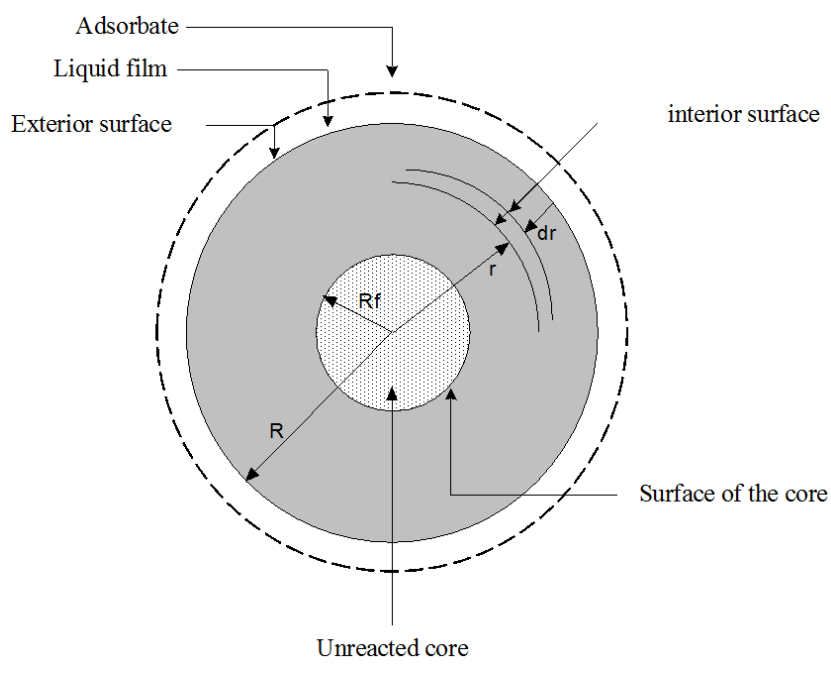

Figure 1. SCM'sdiagraminadsorption.

\subsection{Differential Mass Balance on the Suspension}

The differential mass balance over the system by equating the decrease in adsorbate concentration in the solution with the accumulation of the adsorbate in the adsorbent can be written as:

$$
-V\left(\frac{d C_{t}}{d t}\right)=\frac{W}{\rho_{p}}\left(\frac{d \overline{q_{t}}}{d t}\right)
$$

Where the average solid concentration is defined as follow:

$$
\overline{q_{t}}=\frac{1}{V} \int q d V
$$

\subsubsection{Microscopic Balance of Intraparticle Transport}

The balance of transport - adsorption of adsorbate, through the spherical thin envelop of a radius $r$ and a thickness $\partial r$, is described by the following equation of continuity:

$$
\frac{\varepsilon_{p}}{r^{2}} \frac{\partial}{\partial r}\left(r^{2} D_{e} \frac{\partial C}{\partial r}\right)-\left(1-\varepsilon_{p}\right) \rho \frac{\partial q}{\partial t}=\varepsilon_{p} \frac{\partial C}{\partial t}
$$

The initial conditions are:

$$
\begin{aligned}
& C=0 \quad \text { at } t=0, \quad 0 \leq r<R \\
& C=C_{0} \quad \text { at } t=0, r=R
\end{aligned}
$$

The boundary conditions are:

On the particle's surface $(\mathrm{r}=\mathrm{R})$, the mass flow's continuity can be written as:

$$
\left.D_{e} \frac{\partial C}{\partial r}\right|_{r=R}=k_{f}\left(C_{\mathrm{L}}-C_{\mathrm{s}}\right), r=R, t>0
$$

At the interface $\left(\mathrm{r}=\mathrm{R}_{\mathrm{f}}\right)$, by supposing that the adsorption process is of order $\mathrm{n}$, we can write: 


$$
\left.D_{e} \frac{\partial C}{\partial r}\right|_{r=R_{f}}=k_{s} C_{f}^{n}, r=R_{f}, t>0
$$

The equilibrium inside the particle is supposed local:

$$
q(r, t)=f(C(r, t))
$$

Where: $f$ is an isothermal equilibrium relation.

When the internal diffusion is the limited step, the transport equation for the species in the outer shell region become:

$$
\frac{D_{e}}{r^{2}} \frac{\partial}{\partial r}\left(r^{2} \frac{\partial C}{\partial r}\right)=0, \quad R_{f}(t) \leq r \leq R
$$

The total quantity adsorbed by the particle is expressed as follows:

$$
q_{a d s}(t)=\frac{1}{V_{p}} \int_{R_{f}(t)}^{R} q(r, t) 4 \pi r^{2} d r
$$

Coupling the adsorbate to the interface with adsorption is written as:

$$
\frac{d q_{a d s}(t)}{d t}=\left.4 \pi R^{2} D_{e} \frac{\partial C(r, t)}{\partial r}\right|_{r=R}
$$

\subsubsection{Case of a Control by the External Transport and the Internal Diffusion}

The mass transfer from external liquid phase can be written as:

$$
N^{*}(t)=4 \pi R^{2} k_{f}\left(C_{t}-C_{e t}\right)
$$

The internal diffusion of solute through the pores obeys to Fick's law, after integration:

$$
N^{*}(t)=\frac{4 \pi D_{e} C_{e t}}{\frac{1}{R_{f}}-\frac{1}{R}}
$$

Themassbalanceonasphericalelementofadsorbateparticleca nbewrittenas:

$$
N^{*}(t)=-4 \pi R_{f}^{2} \rho_{p} q_{e t} \frac{d R_{f}}{d t}
$$

The average concentration on adsorbent particle can be written as:

$$
\overline{q_{t}}=q_{e t}\left[1-\left(\frac{R_{f}}{R}\right)^{3}\right]
$$

The dimensionless terms used for simplification are given in Table 1:
Table 1. Dimensionless terms.

\begin{tabular}{lll}
\hline \multicolumn{2}{l}{ Dimensionless terms } & Expression \\
\hline Symbol & Definition & \\
\hline$R^{*}$ & Radius of concentration front & $R^{*}=\frac{R_{f}}{R}$ \\
$C_{t}{ }^{*}$ & Liquid phase concentration at time t & $C_{t}^{*}=\frac{C_{t}}{C_{0}}$ \\
$C_{e t}{ }^{*}$ & $\begin{array}{l}\text { Equilibrium liquid phase concentration at } \\
\text { time t }\end{array}$ & $C_{e t}^{*}=\frac{C_{e t}}{C_{0}}$ \\
\hline
\end{tabular}

In order to represent the equilibrium relation between solid and liquid phase concentration, the well-known Freundlich isotherm is used:

$$
q_{e t}=k_{F}\left(C_{e t}\right)^{1 / n_{F}}=K_{F}^{*}\left(C_{e t}^{*}\right)^{1 / n_{F}}
$$

Taking the derivative of equation (16) by dimensionless time $\tau$, we get the following relation:

$$
\frac{d q_{e t}}{d \tau}=\frac{K_{F}^{*}}{n_{F}}\left(C_{e t}^{*}\right)^{1 / n_{F}-1} \frac{d C_{e t}^{*}}{d \tau}
$$

Simplifying equations (12) and(13),we obtain:

$$
C_{e t}^{*}=\frac{B i\left(1-R^{*}\right) C_{t}^{*}}{R^{*}+B i\left(1-R^{*}\right)}
$$

Simplifying equations (14) and (15) in terms of the parameters in dimensionless form:

$$
\frac{d C_{t}^{*}}{d \tau}+C h\left(1-R^{* 3}\right) \frac{d q_{e t}}{d \tau}=3 C h q_{e t} R^{* 2} \frac{d R^{*}}{d \tau}
$$

Incorporating equation (12) in Eq.(14), we obtain:

$$
\frac{d R^{*}}{d \tau}=\frac{-B i\left(C_{0} / \rho q_{e t}\right)\left(C_{t}^{*}-C_{e t}^{*}\right)}{R^{* 2}}
$$

By combining equations (17), (18) and (19), the following expression is obtained:

$$
\frac{d C_{t}^{*}}{d \tau}=\frac{N\left(C_{t}^{*}, R^{*}\right)}{M\left(C_{t}^{*}, R^{*}\right)} \frac{d R^{*}}{d \tau}
$$

where:

$$
\begin{gathered}
M=1+C h\left(1-r^{3}\right) \frac{K_{F}^{*}}{n_{F}}\left(C_{e t}^{*}\right)^{1 / n_{F}-1} \frac{B i(1-r)}{[r+B i(1-r)]} \\
N=3 C h Y_{e t} r^{2}+\frac{K_{F}^{*}}{n_{F}}\left(C_{e t}^{*}\right)^{1 / n_{F}-1} \frac{C h B i\left(1-r^{3}\right) C_{t}^{*}}{[r+B i(1-r)]^{2}}
\end{gathered}
$$

The initial conditions for equations (20) and (21) are taken 
as $\mathrm{C}_{\mathrm{t}}^{*}=1.0$ and $\mathrm{R}^{*}=0.999$ (rather than $\mathrm{r}=1.0$ in order to avoid singularity in the process of computation) at $\tau=0.0$. These equations can be solved simultaneously to find the time evolution of bulk concentration, provided all other process parameters are known.

The two still unknown kinetic parameters, the external mass transfer coefficient $\left(\mathrm{k}_{\mathrm{f}}\right)$ and internal effective diffusivity $\left(D_{p}\right)$, can be estimated by using a suitable global optimization technique in order to achieve the best fit condition of model predictions with experimental results.

The estimated external mass transfer coefficient may be correlated also as follows:

$$
k_{f}=c \times N^{\alpha}
$$

\subsection{Computational Methodology}

Equations (20) and (21) are numerically solved by fourth order Runge-Kutta solved by Runge-Kutta (2-3) method using a tested step size of $\mathrm{d} \tau=10^{-4}$. The two process parameters $\mathrm{k}_{\mathrm{f}}$ (the liquid phase masse transfer coefficient $(\mathrm{m} / \mathrm{s})$ ) and $\mathrm{D}_{\mathrm{p}}$ (the effective diffusion coefficient in the adsorbent $\left.\left(\mathrm{m}^{2} / \mathrm{s}\right)\right)$ were estimated. At every time point of measurements, the calculated and experimental values of the concentration are compared and sum of square errors (SSE) functional is calculated using equation (25).

$$
S S E=\sum_{i=1}^{n}\left(C_{t, i}^{* \bmod e l}-C_{t, i}^{* \exp }\right)^{2}
$$

The final sets of the parameters are obtained by minimizing SSE function. The optimization problem is solved based on the preset function ode23. The entire computational work was performed in MATLAB platform.

\section{Materials and Methods}

\subsection{Activated Carbons Preparations}

Two activated carbons used as adsorbents were manufactured in our Laboratory from olive stones and prepared by prepared by chemical activation with phosphoric acid (COSAC) [22] and combined activation; impregnation with phosphoric acid and activation with steam vapor(MOSAC) [23].

COSAC preparation: Raw-milled olive stones were impregnated with a phosphoric acid solution (50\% by weight) at $110{ }^{\circ} \mathrm{C}$ for $9 \mathrm{~h}$. After drying, the impregnated material was subjected to thermal activation at $410^{\circ} \mathrm{C}$ for 150 min in a vertical tubular reactor feed by a stream of nitrogen and heated by electric furnace.

MOSAC preparation: waste olive stones were impregnated with a phosphoric acid solution in the same conditions as previous. After drying, the impregnated material was carbonized in a vertical tubular reactor feed by a mixture stream of steam water and nitrogenand heated by electric furnace at $170^{\circ} \mathrm{C}$ during $30 \mathrm{~min}$ then at $380^{\circ} \mathrm{C}$ during 150 $\min$.

The obtained activated carbons were washed thoroughly with distillate water to eliminate impurities, dried at $60{ }^{\circ} \mathrm{C}$ for $24 \mathrm{~h}$ and then sieved.

\subsection{Activated Carbons Characterization}

Nitrogen adsorption-desorption isotherms were measured using an automatic Sorptiometer Autosorb-1CQuantachrome apparatus at $77 \mathrm{~K}$ and in the range of relative pressure from $10^{-5}$ to 1.0 . Total surface area was determined using the Brunauer-Emmett-Teller (BET) equation. The micropore diameter and micropore volume were calculated by the Dubinin-Radushkevich (DR) equation. SEM micrograph was carried out to show the pore structure of obtained activated carbons.

\subsection{Equilibrium Adsorption Isotherms}

Adsorption equilibrium isotherms of salicylic acid, chosen as model molecule of aromatic compounds were all performed at the optimum $\mathrm{pH}$-value of 2.7 and temperature at $40^{\circ} \mathrm{C}$. A weight of $0.2 \mathrm{~g}$ of dry $\mathrm{AC}$ with an average diameter of $0.815 \mathrm{~mm}$ was placed directly into $250 \mathrm{~mL}$ conical flask. Then, $200 \mathrm{~mL}$ of aqueous solutions of $\mathrm{SA}$ with certain concentrations $\left(\mathrm{C}_{0}, \mathrm{mg} / \mathrm{L}\right)$ ranging from $20 \mathrm{mg} / \mathrm{L}$ to 500 $\mathrm{mg} / \mathrm{L}$ were added in adsorption systems. The flasks were being agitated continuously during $48 \mathrm{~h}$ at $300 \mathrm{rpm}$. The concentration $\left(\mathrm{C}_{\mathrm{e}}, \mathrm{mg} / \mathrm{L}\right)$ of the SAin aqueous phase was determined by UV absorption at $259 \mathrm{~nm}$ wave-length using a calibrated UV-Visible spectrophotometer.

The amount of SA adsorbed per unit mass of AC could be determined with equation (26):

$$
q e=\frac{V\left(C_{0}-C_{\mathrm{e}}\right)}{\mathrm{m}}
$$

where $\mathrm{C}_{0}$ and $\mathrm{C}_{\mathrm{e}}$ are the initial and equilibrium metal concentration $(\mathrm{mg} / \mathrm{L}), \mathrm{m}$ is the mass of $\mathrm{AC}(\mathrm{g}), \mathrm{V}$ is the volume of solution (L) and $\mathrm{q}_{\mathrm{e}}$ is the equilibrium adsorption capacity $(\mathrm{mg} / \mathrm{g})$.

\subsection{Adsorption Kinetics}

Effects of AC particle size (dp: $0.1125 \mathrm{~mm}, 0.8150 \mathrm{~mm}$ and $1.8000 \mathrm{~mm}), \mathrm{SA}$ initial concentration $\left(\mathrm{C}_{0}: 50 \mathrm{mg} / \mathrm{L}-300\right.$ $\mathrm{mg} / \mathrm{L})$ and stirring velocity (100 rpm - $600 \mathrm{rpm})$ were studied with fixed adsorbent dose of $1.4 \mathrm{~g}$ of $\mathrm{AC} / \mathrm{L}$ in a batch mixed suspension with $1.4 \mathrm{~L}$ of solution. The temperature of the suspension was maintained at $40^{\circ} \mathrm{C}$ by using a thermostatic bath. Solution samples of $2 \mathrm{~mL}$ volume were withdrawn at a pre-set time intervals then SA concentration was measured.

Each experiment was carried out in duplicates and the average results are presented here.

\section{Results}

The systems considered are salicylic acid (SA), as a solute, adsorbed by the two prepared activated carbons (COSAC and 
MOSAC) and a commercial AC of Norit type (NORIT). So, for that three systems are considered: salicylic acid (SA)COSAC, salicylic acid (SA) - MOSAC and salicylic acid (SA)-NORIT.

The main characteristics of the activated carbons used are illustrated in Table 2. From values listed in this table, one can observe that micropore volumes follow the following trend: NORIT $>$ COSAC $>$ MOSAC. This order is not consistent with the $\mathrm{S}_{\mathrm{BET}}$ surface areas and MOSAC shows the higher specific surface area of $1410 \mathrm{~m}^{2} / \mathrm{g}$ and NORIT the lower one.

The SEM image of COSAC (Figure 2a) shows that the microscopic shape of COSAC is an agglomeration of submicrometric particles.The SEM image of MOSAC (Figure

2b) shows softened texture and fewer micropores as compared as COSAC. While NORIT activated carbon presents a surface roughness (Figure 2c).

Table 2. Characteristics of activated carbons.

\begin{tabular}{llll}
\hline AC & COSAC & MOSAC & NORIT \\
\hline Characteristics & & & \\
Bulkdensity $\left(\mathrm{g} / \mathrm{cm}^{3}\right)$ & 0.55 & 0.45 & 0.60 \\
Volumeofmicropores $\left(\mathrm{cm}^{3} / \mathrm{g}\right)$ & 0.463 & 0.321 & 0.479 \\
Volumeofmesopores $\left(\mathrm{cm}^{3} / \mathrm{g}\right)$ & 0.014 & 0.298 & 0.069 \\
Totalporesvolume $\left(\mathrm{cm}^{3} / \mathrm{g}\right)$ & 0.477 & 0.619 & 0.548 \\
Averageporesdiameter(nm) & 1.835 & 1.905 & 2.219 \\
SpecificsurfaceBET $\left(\mathrm{m}^{2} / \mathrm{g}\right)$ & 1040 & 1410 & 989 \\
\hline
\end{tabular}

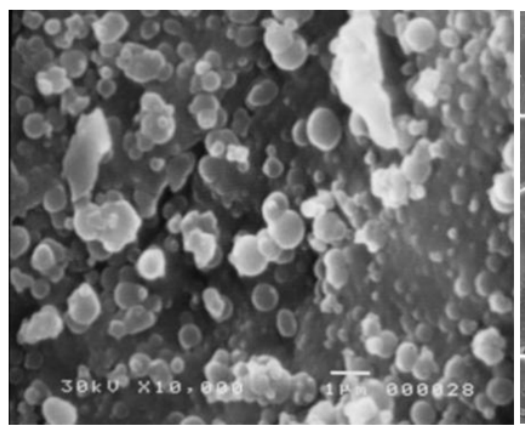

(a)

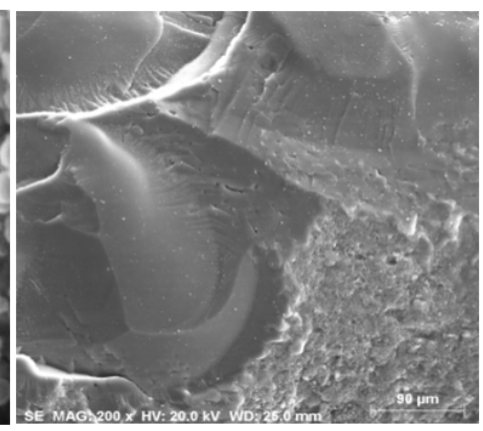

(b)

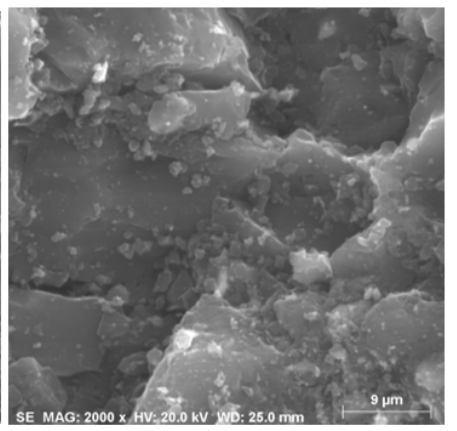

(c)

Figure 2. Scanning electron micrographs of $a$ : COSAC, $b:$ MOSAC, and $c$ : NORIT.

\subsection{Adsorption Isotherms}

Equilibrium adsorption isotherms of SA onto COSAC, MOSAC and NORIT are given in Figure 3.Isotherms show important adsorption capacities of ACs to remove SA and adsorbed amounts are: $236 \mathrm{mg} / \mathrm{g}, 194 \mathrm{mg} / \mathrm{g}$ and $175 \mathrm{mg} / \mathrm{g}$ for NORIT, MOSAC and COSAC, respectively.

In order to obtain Freundlich parameters $\left(\mathrm{K}_{\mathrm{F}}((\mathrm{mg} / \mathrm{L})(\mathrm{L} / \mathrm{g})(1 / \mathrm{n}))\right.$ and $\left.\mathrm{n}_{\mathrm{F}}\right)$, Freundlich model (equation (16)) was used to fit the equilibrium adsorption data of SA adsorption onto ACs. Freundlich parameters and correlation coefficients are illustrated in Table 3. High correlation coefficients values indicate that experimental isotherm data satisfactory follow Freundlich model.

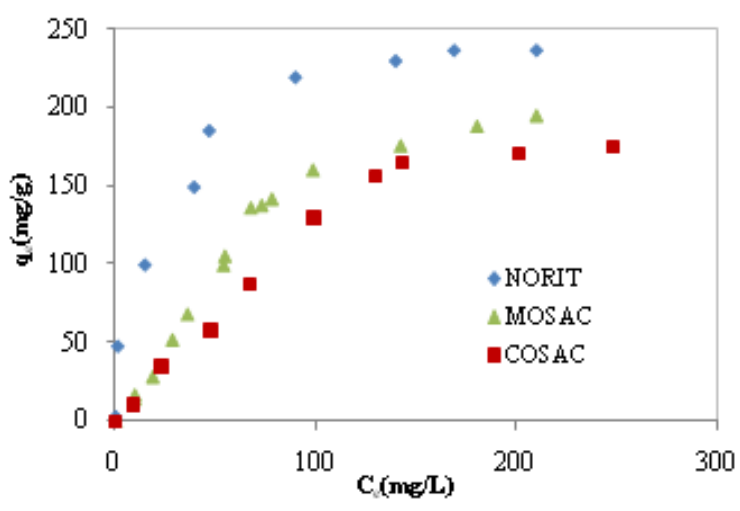

$\left(\mathrm{T}=40^{\circ} \mathrm{C}, \mathrm{pH}=2.7, \mathrm{~V}=200 \mathrm{~mL}, \mathrm{~m}=0.2 \mathrm{~g}\right)$

Figure 3. Adsorption isotherms of SA onto COSAC, MOSAC and Norit.
Table 3. Freundlich isotherm parameters.

\begin{tabular}{llll}
\hline Freundlich model & $\mathbf{K}_{\mathbf{F}}(\mathbf{m g} / \mathbf{L})(\mathbf{L} / \mathbf{g})(\mathbf{1} / \mathbf{n})$ & $\mathbf{n}_{\mathbf{F}}$ & $\mathbf{R}^{\mathbf{2}}$ \\
\hline COSAC & 7.4137 & 1.6716 & 0.9851 \\
MOSAC & 34.3700 & 2.9799 & 0.9934 \\
NORIT & 38.3148 & 2.9799 & 0.9899 \\
\hline
\end{tabular}

For kinetic study dimensionless concentration-time data generated numerically after solving equations (20) and (21) with simultaneous optimization of mentioned parameters were compared with experimental values.

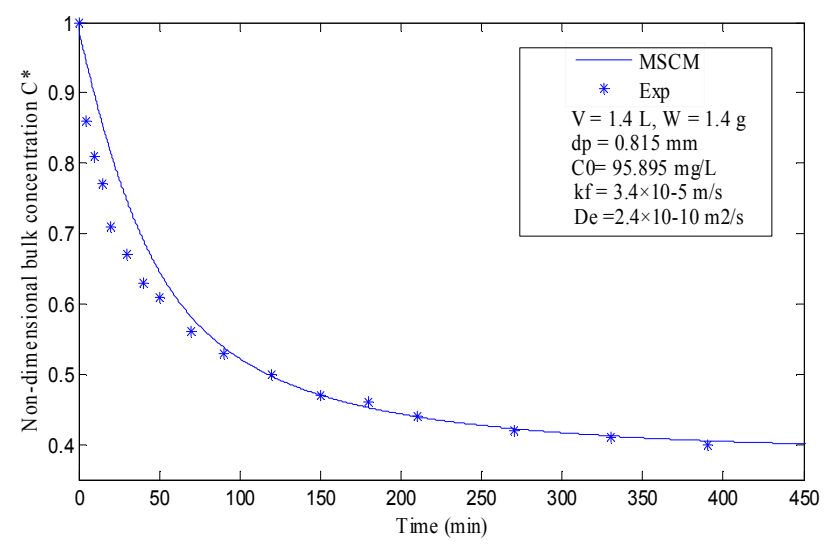

Figure 4. Adsorption of AS onto COSAC.

\subsection{Estimation of Kinetic Parameters of Transport for Different Types of $A C$}

The system salicylic acid (SA)-COSAC and the Freundlich isotherm constants were considered. For $\mathrm{V}=1.4 \mathrm{~L}, \mathrm{~W}=1.4 \mathrm{~g}$ 
and $\mathrm{d}_{\mathrm{p}}=0.815 \mathrm{~mm}$, the concentration decay data for $\mathrm{C}_{0}=$ $95.895 \mathrm{mg} / \mathrm{L}$ was used to determine the unknown process parameters using the above numerical procedure as shown in the Figure 4. The estimated values of the liquid phase mass transfer coefficient $\left(\mathrm{k}_{\mathrm{f}}\right)$ and the effective diffusion coefficient in the adsorbent $\left(\mathrm{D}_{\mathrm{e}}\right)$ are determined and have the value of $3.4 \times 10^{-5} \mathrm{~m} / \mathrm{s}$ and $2.4 \times 10^{-10} \mathrm{~m}^{2} / \mathrm{s}$ respectively. $\mathrm{k}_{\mathrm{f}}$ and $\mathrm{D}_{\mathrm{p}}$ values were used to simulate the adsorption kinetics for different operating conditions.

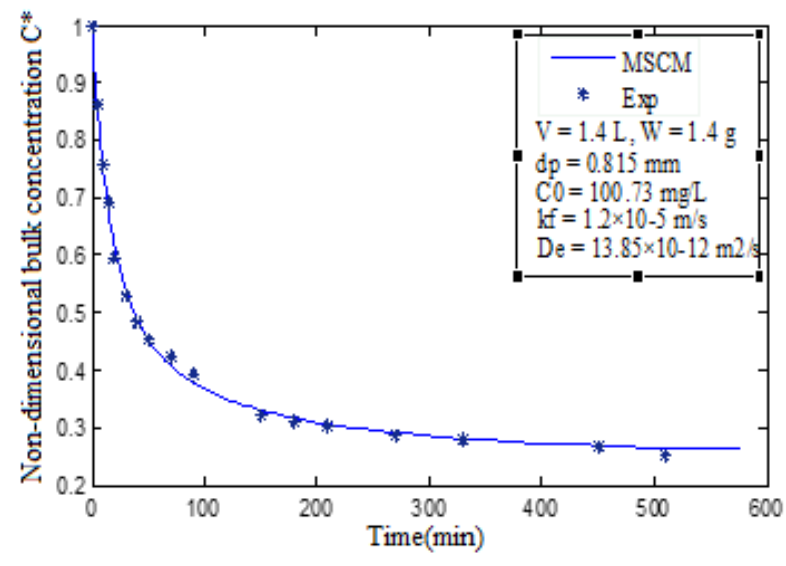

Figure 5. AdsorptionofASontoMOSAC.

The system the salicylic acid (SA) - MOSAC and the Freundlich isotherm constants are considered. For $\mathrm{V}=1.4 \mathrm{~L}$, $\mathrm{W}=1.4 \mathrm{~g}$ and $\mathrm{d}_{\mathrm{p}}=0.815 \mathrm{~mm}$, the concentration decay data for $\mathrm{C}_{0}=100.73 \mathrm{mg} / \mathrm{L}$ was used to determine the unknown process parameters using the above numerical procedure as shown in the Figure 5. The estimated values of the parameters are as follows: $\mathrm{k}_{\mathrm{f}}=1.2 \times 10^{-5} \mathrm{~m} / \mathrm{s}$ and $\mathrm{D}_{\mathrm{e}}=$ $13.85 \times 10^{-12} \mathrm{~m}^{2} / \mathrm{s}$. These values $\mathrm{k}_{\mathrm{f}}$ and $\mathrm{D}_{\mathrm{p}}$ are used to simulate the adsorption kinetics for different operating conditions.

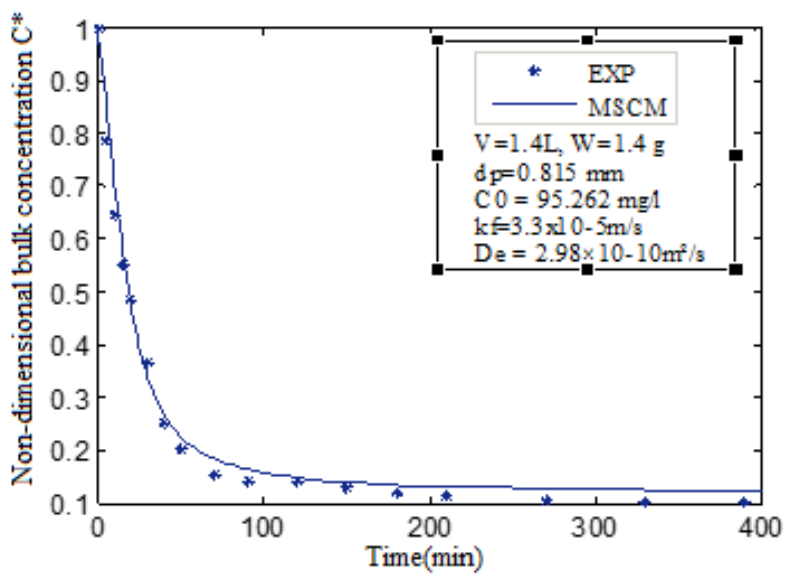

Figure 6. Adsorption of AS onto NORIT.

The system of salicylic acid (SA) - NORIT and the Freundlich isotherm constants are considered. For $\mathrm{V}=1.4 \mathrm{~L}$, $\mathrm{W}=1.4 \mathrm{~g}$ and $\mathrm{d}_{\mathrm{p}}=0.815 \mathrm{~mm}$, the concentration decay data for $\mathrm{C}_{0}=95.262 \mathrm{mg} / \mathrm{L}$ was used to determine the unknown process parameters using the above numerical procedure as shown in the Figure 6 . The estimated values of the parameters are as follows: $\mathrm{k}_{\mathrm{f}}=3.3 \times 10^{-5} \mathrm{~m} / \mathrm{s}$ and $\mathrm{D}_{\mathrm{e}}=$ $2.98 \times 10^{-10} \mathrm{~m}^{2} / \mathrm{s}$. These values of $\mathrm{k}_{\mathrm{f}}$ and $\mathrm{D}_{\mathrm{p}}$ are used to simulate the adsorption kinetics for different operating conditions.

From Figure 4-6, it is clear that the simulated bulk concentration-time curves follow the experimental decay curves closely. Under the same kinetic adsorption conditions of solid rate and agitation, the estimated values of the kinetic parameters (Table 4) show that the external mass transfer coefficient $\left(\mathrm{K}_{\mathrm{f}}\right)$ is practically constant for the three ACs. While, effective diffusion coefficient values $\left(D_{e}\right)$ were found to be varied with the type of AC. It's clear that the MOSAC has an effective diffusivity approximately 20 times lower than that of the COSAC. This result is foreseeable because of the very microporous texture of MOSAC as compared to the COSAC and NORIT.

Table 4. Kinetic parameters of the three ACs.

\begin{tabular}{lll}
\hline Parameters & $\mathbf{k}_{\mathbf{F}}$ & $\mathbf{D}_{\mathbf{e}}$ \\
\hline COSAC & $3.4010^{-05}$ & $2.4010^{-10}$ \\
MOSAC & $1.2010^{-05}$ & $13.8510^{-12}$ \\
NORIT & $3.3010^{-05}$ & $2.9810^{-10}$ \\
\hline
\end{tabular}

\subsection{Parametric Study}

The various parameters that can affect the adsorption kinetics are the particle size of adsorbent, the initial adsorbate concentration in liquid phase and the stirring velocity.

\subsubsection{Effect of the Adsorbent Particle Size}

The effects of particle size of MOSAC and NORIT on the non-dimensional bulk concentration and the non-dimensional radius are presented in Figure $7(\mathrm{a}-\mathrm{b})$ and Figure $8(\mathrm{a}-\mathrm{b})$, respectively. From these figures, it is clear that the modified SCM fit experimental results perfectly. Figure $7 \mathrm{a}$ and Figure 8 a show that the rate or decay of bulk SA concentration is faster for lower particle size due to the greater accessibility to pores and increases in contact surface because with smaller particle size, the outer area is more important for constant weight of AC.

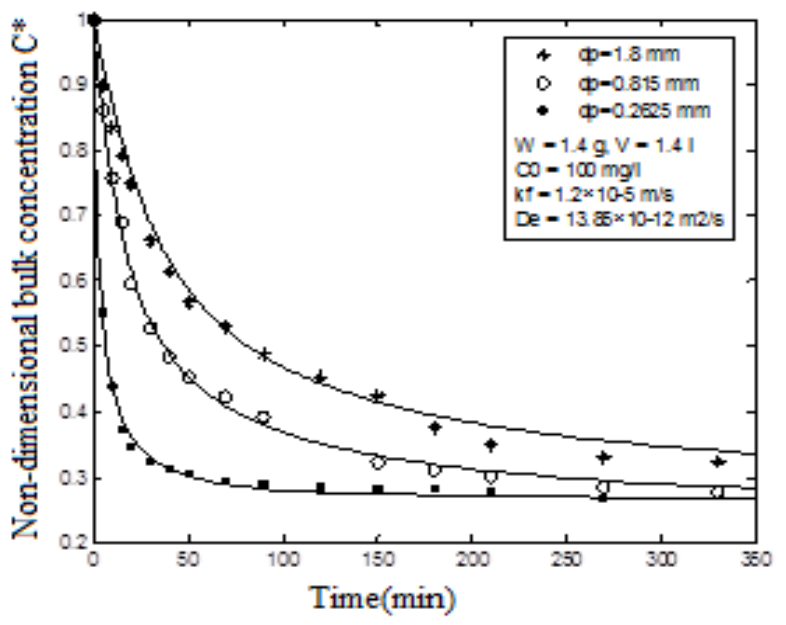

Figure 7a. Effect of adsorbent particle size on concentration decay (AS$M O S A C)$. 


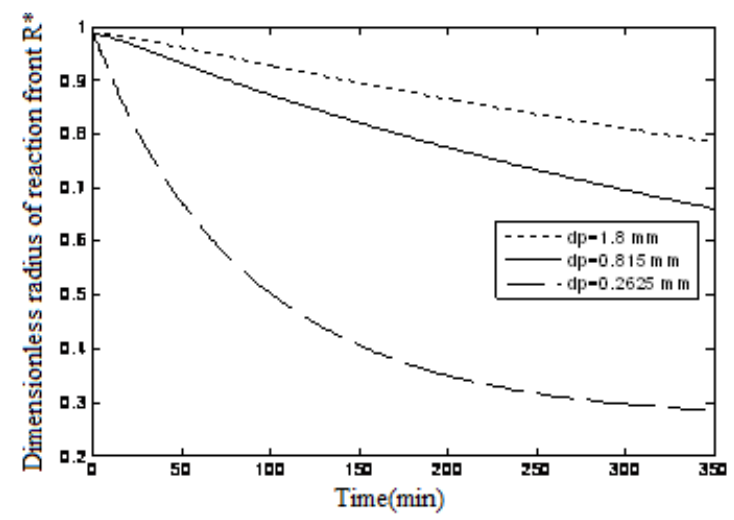

Figure 7b. Effect of adsorbent particle size on non-dimensionalradius(SA$M O S A C)$

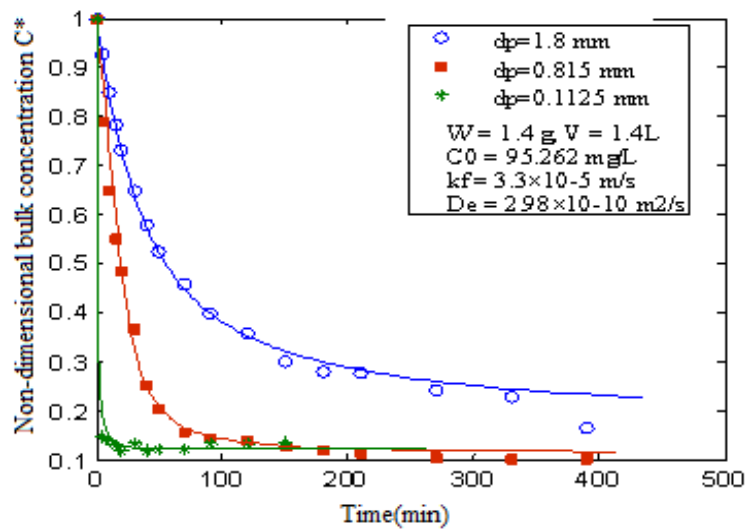

Figure 8a. Effect of adsorbent particle size on non-dimensional bulk concentration (AS-NORIT).

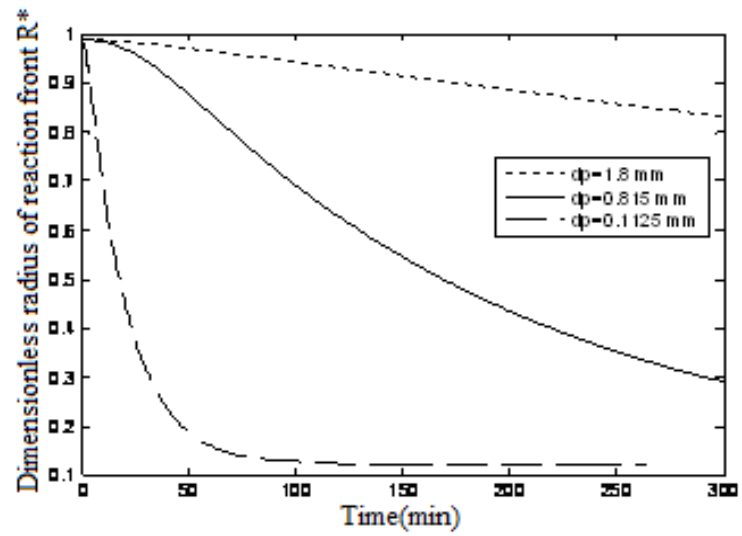

Figure 8b. Effect of adsorbent particle size on non-dimensional radius (ASNORIT).

Despite the important surface area of MOSAC $\left(1410 \mathrm{~m}^{2} / \mathrm{g}\right)$ as compared to NORIT $\left(989 \mathrm{~m}^{2} / \mathrm{g}\right)$, the examination of kinetic parameters: $k_{f}(\mathrm{~m} / \mathrm{s})$ and $D_{p}\left(\mathrm{~m}^{2} / \mathrm{s}\right)$ shows that the adsorption of SA onto NORIT is more rapid than the adsorption onto MOSAC. This can be due to the difference in micropores and mesopores volumes and adsorption is faster for microporous AC. Even, Figure 7a and Figure 8a show that the adsorption front progresses rapidly with the smaller particle diameter of AC. Furthermore, the rate of decrease of the non-dimensional radius is less for the smaller particle size

\section{of NORIT and MOSAC.}

The comparison between kinetic parameters $\mathrm{k}_{\mathrm{f}}(\mathrm{m} / \mathrm{s})$ and $\mathrm{D}_{\mathrm{e}}(\mathrm{m} / \mathrm{s})$ estimated for both ACs (NORIT and MOSAC) (Table 5) shows that $k_{f}$ values are superior than $D_{e}$ values, thus intraparticle diffusion is the predominant limiting step for the adsorption of salicylic acid on microporous AC.

Table 5. Estimated kinetic parameters values.

\begin{tabular}{lll}
\hline & $\mathbf{k}_{\mathbf{f}}(\mathbf{m} / \mathbf{s})$ & $\mathbf{D}_{\mathbf{e}}\left(\mathbf{m} / \mathbf{s}^{\mathbf{2}}\right)$ \\
\hline NORIT & $3.3010^{-05}$ & $2.4810^{-10}$ \\
MOSAC & $1.2010^{-05}$ & $13.8510^{-12}$ \\
\hline
\end{tabular}

\subsubsection{Effect of Initial SA Concentration}

Using NORIT as adsorbent, the effect of the initial SA concentration on the bulk concentration decay and on the non-dimensional radius $\left(\mathrm{R}^{*}\right)$ are presented in Figure $9 \mathrm{a}$ and Figure $8 \mathrm{~b}$, respectively. From Figure $8 \mathrm{a}$, one can note the good fitting of the modified SCM to experimental data. This figure shows that with the decrease in initial SA concentration in the bulk solution, the rate of concentration decay in liquid phase increases, so the adsorption rate increases.

Figure 9.b shows that the unadsorbed portion of $\mathrm{AC}$ is decreasing at a more rapidly rate for higher initial salicylic acid concentration due to the higher availability of SA molecules.

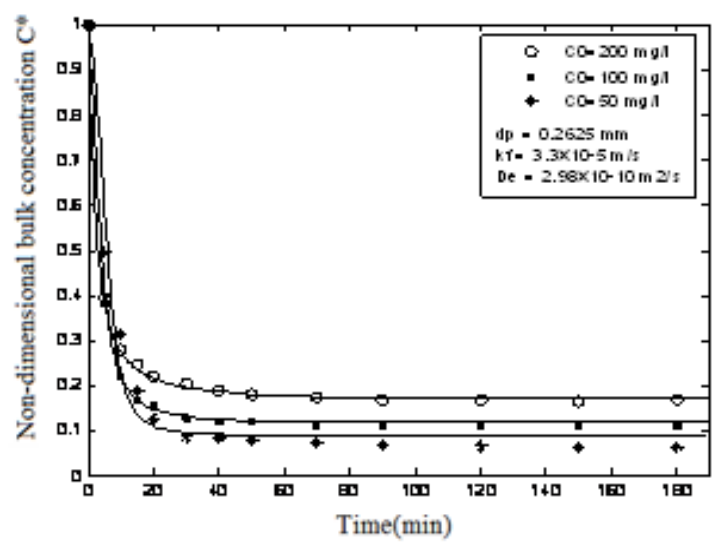

Figure 9a. Effect of the initial adsorbate concentration on concentration decay (AS-NORIT).

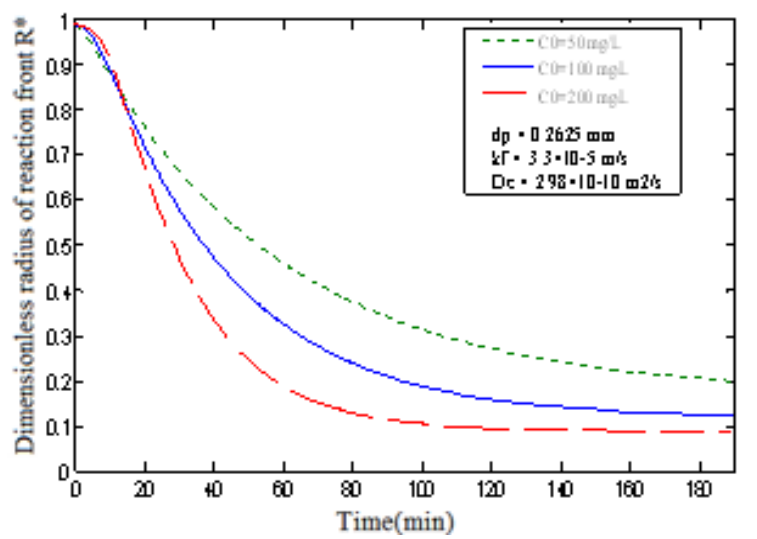

Figure 9b. Effect of the initial adsorbate concentration on non-dimensional radius (AS-NORIT). 


\subsubsection{Effect of the Stirring Velocity}

Effect of the stirring velocity on the bulk concentration decay and on the non-dimensional radius for the adsorption of SA onto COSAC and NORIT is presented in Figure 10. and Figure 11, respectively. Results show that the modified SCM perfectly fitted the experimental data. Figure 10 a and Figure 11a show that for stirring velocity values bellow 500 rpm, no important difference in the rate of adsorption decay was observed. However, for stirring velocity value above 500 rpm (Figure10.a), an increase in the stirring velocity until $600 \mathrm{rpm}$ shows an increase in the rate of concentration decay in liquid phase, i.e. an increase in the adsorption rate. Indeed, an increase in the stirring speed, allows having more favorable hydrodynamic conditions for the transfer of material to the grain of the CA. So if the external transfer is performed through a film thickness $\delta$, the latter will decrease when the stirring speed increases. Thus, with increase in initial SA concentration, the reaction front shrinks at a higher rate $[6,18]$.

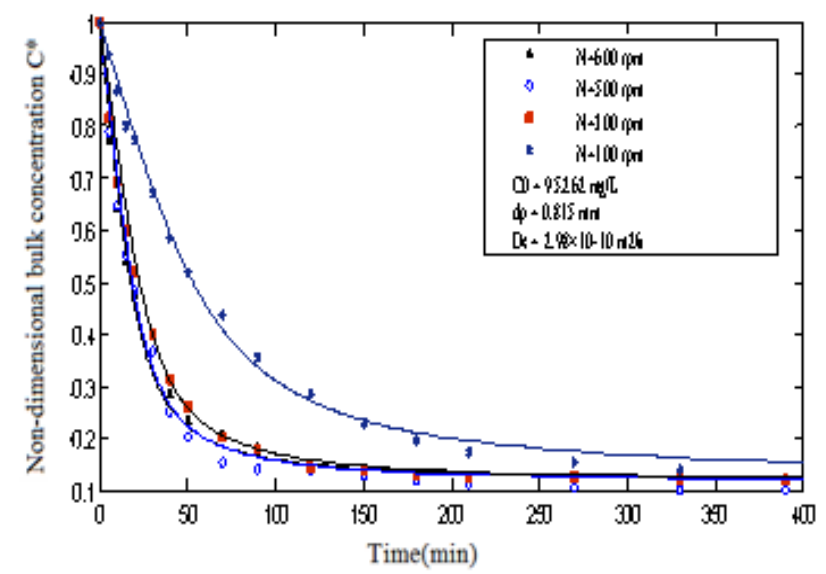

Figure 10a. Effect of the stirring velocity on concentration decay(ASNORIT).

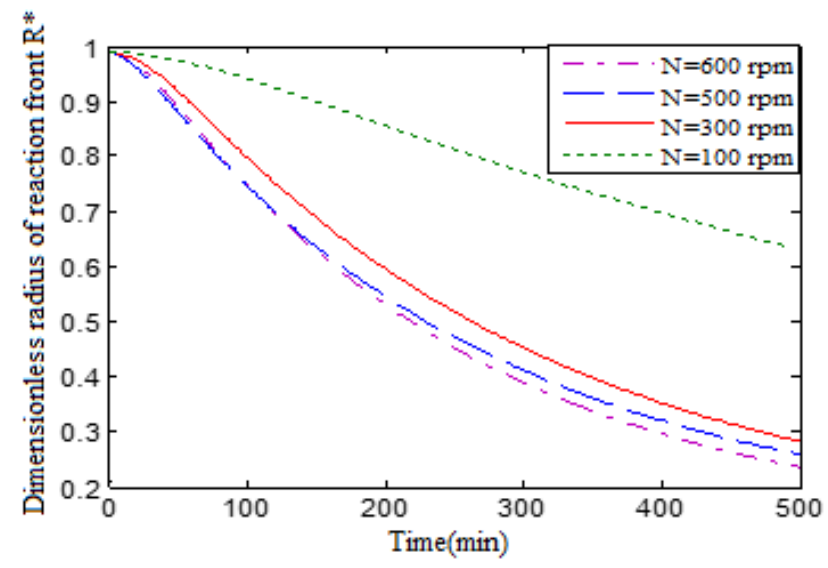

Figure 10b. Effect of the stirring velocity on non-dimensional radius (ASNORIT).

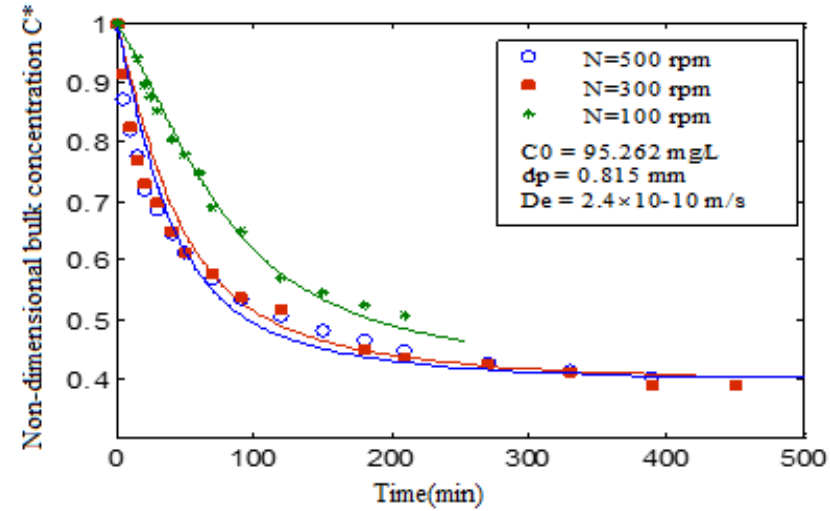

Figure 11a. Effect of the stirring velocity on concentration decay (ASCAGOC)

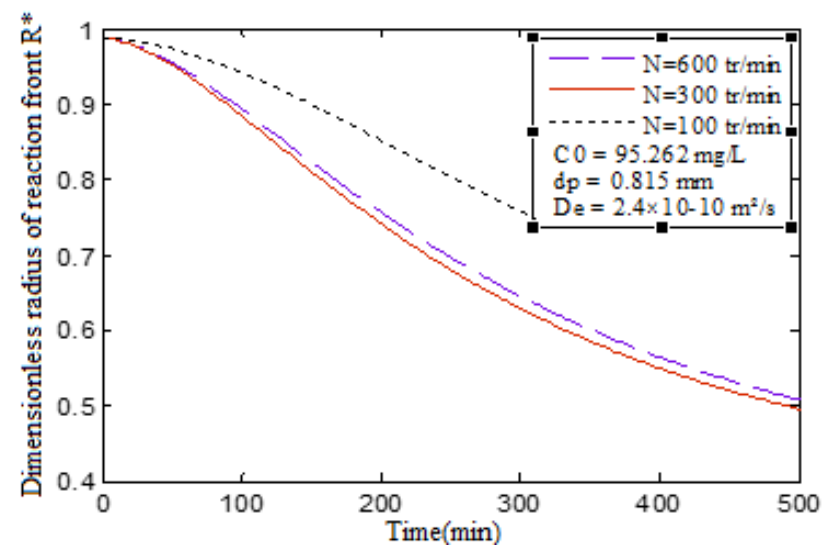

Figure 11b. Effect of the stirring velocity on non-dimensional radius (AS$\operatorname{COSAC)}$.

According to simulation, the estimated external mass transfer coefficients for various stirring velocities and different AC are illustrated in Table 6:

Table 6. Estimated external mass transfer coefficients for various stirring velocities and different $A C$.

\begin{tabular}{lll}
\hline $\begin{array}{l}\text { Stirring velocity } \mathbf{N} \\
(\mathbf{r p m})\end{array}$ & \multicolumn{2}{l}{ External mass transfer coefficient $\mathbf{k}_{\mathbf{f}}(\mathbf{m} / \mathbf{s})$} \\
\cline { 2 - 3 } & NORIT & COSAC \\
\hline 100 & $0.98 \times 10^{-5}$ & $1.28 \times 10^{-5}$ \\
300 & $2.38 \times 10^{-5}$ & $3.13 \times 10^{-5}$ \\
500 & $3.65 \times 10^{-5}$ & $4.44 \times 10^{-5}$ \\
600 & $3.92 \times 10^{-5}$ & - \\
\hline
\end{tabular}

The examination of estimated external mass transfer coefficients values shows that the greater the stirring velocity was, the more significant was the external mass transfer coefficient [12]. Adsorption was more favorable for a stirring velocity of $500 \mathrm{rpm}$ beyond which the kinetics of adsorption remain practically constant. It seems that the external mass transfer of SA to COSAC surface was more rapid than that to NORIT surface due to the higher $\mathrm{S}_{\mathrm{BET}}$ surface area of COSAC; high adsorption sites available on the COSAC surface compared to NORIT.

Calculated constants $\mathrm{c}$ and $\alpha$ (equation (24)) in these conditions are illustrated in Table7. 
Table 7. Constants of the correlation of the external transfer coefficients.

\begin{tabular}{lll}
\hline Constant & $\mathbf{c}$ & $\boldsymbol{\alpha}$ \\
\hline CA & & \\
NORIT & $2.58 \times 10^{-7}$ & 0.79 \\
COSAC & $3.22 \times 10^{-7}$ & 0.80 \\
\hline
\end{tabular}

Results show that the power factor remains constant for both types of activated carbons. This is obvious given that experiments are operated in the same conditions.

\section{Conclusion}

In the present work, performances of olive stones activated carbons and a commercial one were analyzed as adsorbents for the removal of salicylic acid as phenolic compound from aqueous solution. Batch equilibrium and kinetic adsorption studies were conducted. Isotherms are well fitted to Freundlich model and Freundlich parameters were used to validate modified Shrinking Core Model formulated to simulate the process of adsorption in term of kinetic study. It has been observed that the shrinking core model successfully applies batch kinetic adsorption of the salicylic acid on various types of activated carbons and that the extent of adsorption can effectively be explained by the rate of decrease of the unadsorbed portion of the adsorbent (in terms of dimensionless particle radius).

The model is useful to estimate the process parameters; the liquid phase mass transfer coefficient (kf) and the effective diffusion coefficient in the adsorbent (De) which are required for the design of fixed bed adsorber. Results show that $\mathrm{kf}$ and De values are higher for more microporous AC (COSAC) and the rate of adsorption increases with decrease in initial adsorbate concentration, decrease in adsorbent particle size and increase of stirring velocity.

\section{References}

[1] Liu Q. S., Zheng T., Wang P., Jiang J. P., Li N (2010) Adsorption isotherm, kinetic and mechanism studies of some substituted phenols on activated carbon fibers. Chem. Eng. J. 157(2010) 348-356.

[2] Kumar D., Gaur J. P (2011) Chemical reaction- and particle diffusion-based kinetic modeling of metal biosorption by a Phormidium sp.-dominated cyano bacterial mat. Biores. Tech. 102: 633-640.

[3] Tang W., Huang H., Gao Y., Liu X., Yang X., Ni H., Zhang J (2015) Preparation of a novel porous adsorption material from coal slag. Materials and Design 88: 1191-1200.

[4] Frascari D., Bacca A. E. M., Zama F., Bertin L., Fava F., Pinelli D (2016) Olive mill wastewater valorisation through phenolic compounds adsorption in a continuous flow column. Chem Eng J 283:293-303.

[5] Abussaud B., Asmaly H. A., Saleh T. A., Gupta V. K., Laoui T., Atieh M (2015) Sorption of phenol from wasters on activated carbon impregnated with iron oxide, aluminum oxide and titanium oxide. J molecular liq. dx.doi.org/10.1016/j.molliq, 08.044.
[6] Jena P. R., Basu J. K., De S (2004) A generalized shrinking core model for multicomponent batch adsorption processes. Chem. Eng. J. 102:267-275

[7] Kasnejad M. H., Esfandiari A., Kaghazchi T., Asasian N (2012) Effect of pre-oxidation for introduction of nitrogen containing functional on $\mathrm{Cu}$ (II) adsorption, J. Taiwan Inst. Chem. Eng. 43:736-740.

[8] Bohli T., Ouederni A, Fiol N., Villaescusa I (2015) Evaluation of an activated carbon from olive stones used as an adsorbent for heavy metal removal from aqueous phases. C R Chimie 18:88-99.

[9] Gokce Y, Aktas Z (2014) Nitric acid modification of activated carbon produced from waste tea and adsorption of methylene blue and phenol. App Surf Sc 313: 352-359.

[10] Yang Q., Zhao M., Lin L (2016) Adsorption and desorption characteristics of adlay bran free phenolics on macroporous resins, Food Chemistry 194:900-907.

[11] Pritzker M (2004) Modified shrinking core model for uptake of water soluble species onto sorbent particles, Adv. Environ. Res.84:39-453.

[12] Osifo P. O., Webster A., der Merwe H., Neomagus H. W. J. P., der Gun M. A., Grant D. M(2008) The influence of the degree of cross-linking on the adsorption properties of chitosan beads. Bio Tech 99:7377-7382.

[13] Sarkar D., Bandyopadhyay A (2011) Shrinking Core Model in characterizing aqueous Phase dye adsorption. Chem. Eng. Research and Design 89 69-77.

[14] Fernandes Z, Gando-FerreiraL M (2011) Kinetic modeling analysis for the removal of $\mathrm{Cr}(\mathrm{III})$ by Diphonix resin. Chem. Eng. J 172: 623-633.

[15] Traylor S. J., Xu X., Lenhoff A. M (2011) Shrinking-core modeling of binary chromatographic breakthrough. J. Chromatography A 1218:2222-2231.

[16] Knorr T., Kaiser M., Glenk F., Etzold B. J. M (2012) Shrinking core like fluid solid reactions-A dispersion model accounting for fluid phase volume change and solid phase particle size distributions, Chem. Eng. Sc. 69:492-502.

[17] Pritzker M. D (2003) Model for parallel surface and pore diffusion of an adsorbate in a spherical adsorbent particle, Chem. Eng. Sc. $58473-478$.

[18] Jena P. R., De S., Basu J. K(2003) A generalized shrinking core model applied to batch adsorption, Chem. Eng. J. 95 143-154.

[19] Jena P. R., Basu J. K., De S (2004)A generalized shrinking core model for multicomponent batch adsorption processes, Chem. Eng. J. 102 267-275.

[20] Mckay G., EL Guendi M. Nassar M. M (1996) Pore diffusion during the adsorption of dyes onto BAGASSE PITH. Trans. I. Chem. E. B 74.

[21] Liddell K. C (2005) Shrinking core models in hydrometallurgy: What students are not being told about the pseudo-steady approximation, Hydrometallurgy 79: 62- 68 .

[22] Bohli T., Ouederni A (2016) Improvement of oxygencontaining functional groups on olive stones activated carbon by ozone and nitric acid for heavy metals removal from aqueous phase, Environ. Sci. Pollut. Res. DOI 10.1007/s11356-015-4330-0.

[23] Ben Yahia S., Ouederni A (2012) Hydrocarbons Gas Storage on Activated Carbons, Int. J. Chem. Eng. App. 3:3. 